\title{
The Relationship Between Implicitly Political Films and Political Polarization
}

\author{
Jadyn Cantrell ${ }^{1}$
}

${ }^{1}$ Robert A Millikan High School, Long Beach, CA, USA

\section{ABSTRACT}

Throughout history, art has played a vast role in both culture and activism. With the United States having a booming film industry centered in the heart of Los Angeles and spreading all across the country, it is hard to believe that such a huge cultural phenomenon does not impact the viewpoints of United States voters and their decision making at the polls. This study dives into that impact, looking at both quantitative and qualitative research, trying to uncover the influence that implicitly political films have on political polarization and answer the question: what is the relationship between implicitly political feature films released between 2009 and 2019 and political polarization in the United States? The quantitative research of this study exposed a correlation between the year of the presidency and the number of successful implicitly political films that were released per year. The qualitative surveys from this study uncovered that teenagers today do not feel particularly influenced by the movies that they watched growing up, therefore suggesting that if implicitly political films have any effect on political decision making, it is at the subconscious level. As times change and technology improves, it seems that there is no limit to the extent of influence. It is important to understand this influence and its implications before it is too late.

\section{Literature Review}

Over the past decade, technology has become an increasingly important part of our culture. As technology allows information to spread more quickly, the impressionable mind becomes more exposed to political views. Art has always played an important role in socio-cultural movements in the United States, and as technology makes art more accessible, particularly movies, the audience of such movements becomes broader. Historically, United States culture has been riddled with uprisings and social movements. Some films have even been so powerful that they started movements of their own. For example, the film The Birth of A Nation, released in 1915 and based off of the novel The Clansman by Thomas Dixon, portrayed the Ku Klux Klan as heroes who liberated the south from the barbaric "freed people." While Civil Rights organizations such as The National Association for the Advancement of Colored People protested the film and tried to get it banned or censored, the film received wide acclaim and became the first film to ever be shown in the White House under President Woodrow Wilson. The film was so successful that later that year the Ku Klux Klan, inactive since 1872, was reinstated in the United States and began terrorizing people of color across the nation (FacingHistory.org). Likewise, films such as Bambi and The Planet of the Apes stirred their own movements, although far more positive, with Bambi bringing attention to the inhumane practice of trophy hunting and Planet of the Apes bringing attention to the racial injustice in America shortly following the Civil Rights movement of the 60s. Evidently, these films are extremely powerful and have played a great role in shaping the society that produced them, but how have films like these influenced citizens at the polls?

All this speculation led to the question: what is the relationship between implicitly political feature films released between 2009 and 2019 and political polarization in the United States? Knowing the impact that previous films have had on society, it is probable that implicitly political films increase political polarization (i.e. the arguments that spurred after the release of $\mathrm{Bambi}$ ). However, implicitly political films that reach wide audiences may also cause 
a widespread shift towards the advertised belief presented in the movie, such as the increase in Ku Klux Klan action after the release of The Birth of A Nation. Before we can fully answer this question, however, it is important to define what an implicitly political film is. As stated by author Eric Greene, "we need a broader definition of political film that includes any movie that explicitly or implicitly deals with the use of, struggles over, and control of power and privilege or that suggests ways of responding to societal conflict" (Greene). Greene also notes that this new definition applies not only to films such as JFK but also The Lion King. This new definition also includes educational films that are shown in classrooms all over the United States. Often overlooked, educational films can impose views on students starting at a very young age and continue to have influence until students graduate from high school and possibly beyond in both life and higher education (Ellsworth). With this new definition, the range of films that fall under this umbrella greatly broadens, also broadening the role that film plays in society. This also means that the level of depth that studies concerning film and politics must go into is much deeper than realized at first glance.

It is also necessary to understand the role that art has played in past historical movements. In past historical and political movements, art has played many roles including: encouraging social change, uniting activists, expressing values and ideas, communicating ideas to people outside of the movement, attaching emotion to the movement, and setting the tone of the movement (Millbrant). Evidently, art has played a very important role in past political movements, attacking the movement from all angles, particularly the emotional one. Art has the unique ability to showcase ideas in many different lights and impact people in a way so powerful that they feel the need to act. Ever since the invention of the video recorder, movies have played an important role in making history and, as technology increases, that role becomes even more influential.

New technology such as 3D, IMAX, and greater sound and visual quality has led to an overall more immersive viewing experience (Dudkin). This experience can influence viewers to feel more a part of the movie and more deeply connected to the lives of the characters in the movie. As this potential connectivity increases, it becomes easier for filmmakers to express ideas and influence the opinions of the viewers. This means that even seemingly harmless movies such as Disney's Frozen can have implicit political connotations that impact the viewpoints of audience members. Thus, this more recent immersive experience also increases the potential impact that films can have on viewers, making them increasingly more influential to our culture as technology improves. This leads to the conclusion that any film that is not explicitly political is implicitly political. For example, a movie such as $J F K$ can be seen as explicitly political as it very obviously showcases political figures and concepts, while The Lion King can be seen as implicitly political because it still showcases power balances and political relationships, but it does so in a more discrete way. While these styles of films are slightly different, they both fall under the umbrella term of "political film" set by author Eric Greene. However, this study focuses solely on the role that implicitly political films play.

\section{Methodology}

The overall purpose of this study is to answer the question: what is the relationship between implicitly political feature films released between 2009 and 2019 and political polarization in the United States? To fully understand this relationship, a correlational study must be conducted. This correlational study will compare the number of popular implicitly political films released between 2009 and 2019 and the rise or fall of political polarization during that time. For this study, political polarization will refer to the deficit between the percentage of people who declare Democratic party affiliation and the percentage of people who declare Republican party affiliation. Likewise, a successful, implicitly political movie will be considered a movie that is among the fifty highest grossing films within its designated year that does not explicitly deal with the topic of politics through subjects such as war or the presidency. Each year will begin with the top fifty highest grossing movies of that particular year and each movie that explicitly deals with political topics will be subtracted from the overall total. This number will then be divided by fifty, giving the total percentage out of the top fifty grossing films of a given year that were implicitly political.

This correlational study will showcase the impact, if any, that implicitly political films have on political polarization. The period being studied is also important because it will provide information that is relevant to today's 
social and political climate. It will also present new information that has yet to be studied. Also, in order to truly understand the direct impact that films play on teens, a survey is necessary. In the survey, teenagers aged 16-18 will be asked to take a Likert style survey in which they rate their views on various forms of media and the impact that each type of media plays on their political views. A Likert style survey is the most effective way to convey teenage viewpoints because it will quantify opinions and make them more concrete. This will also eliminate the gray area that is often associated with politics, creating a base level hierarchy of the political influences that teenagers are exposed to. Questions will ask the teenagers to rank their level of agreement with a statement on a scale of 0-5. Some statements include: My political views are shaped by the movies that I watched growing up, my political views are shaped by my friends, I am a Republican, I am a Democrat, and I am undecided. Rating his or her agreement with these statements will help clarify the political background of the particular student and the influence that led to this background. It will also help clarify the strength each influence has in relevance to the others, helping decipher if movies are the most important influence or if another factor is. In other words, it will showcase what type of media teens believe has influenced their beliefs most and if movies play a large role in their political views. The survey will also contain some red herring questions to ensure that the students will remain unbiased during the survey. It is imperative that the survey must be conducted within the stated age group because it is important to understand the experienced yet still impressionable mind. This age group is also the target demographic because they grew up in the stated time frame of 2009 through 2019 and have therefore been exposed to the most prevalent influences of the decade. This will help contextualize the viewpoints of the target demographic.

Together these methods will help decipher the political influences present in implicitly political films. The correlational study will provide a quantitative view of the relationship between implicitly political films and political polarization occurring during the stated time frame, while the survey will provide a more intimate view of the people that are directly affected by this phenomena, getting an insider perspective on their opinions and influences. These two methods will work together to showcase a well-rounded viewpoint of the direct influences that the target demographic faces and how these influences reflect political decision making. This will help illustrate the impact that implicitly political films have on political polarization and if that is truly the greatest influence that rising voters face.

\section{Results}

\section{Correlation}

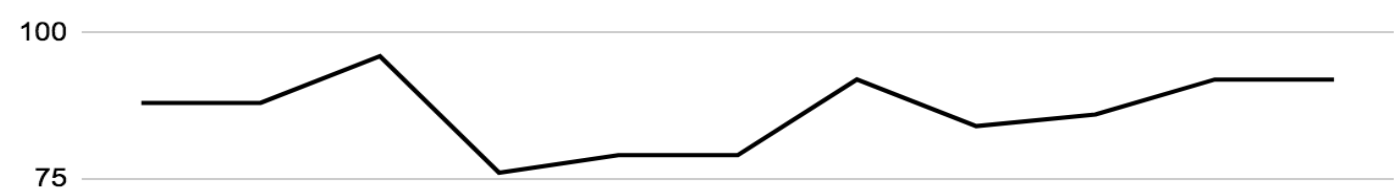

75

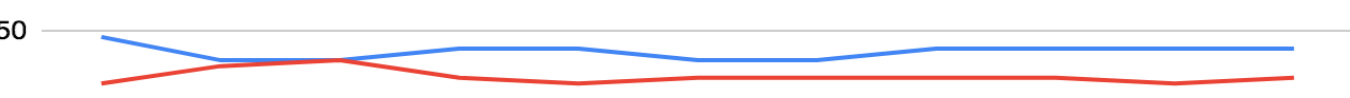

25

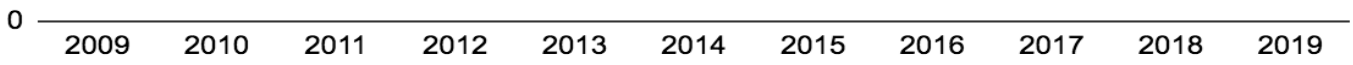

Figure 1. Political Party Polarization and Implicitly Political Films 
In Figure 1, the black line represents the percent of successful implicitly political films that were released by year. The blue line represents the percent of voters who identified with the Democratic political party for each given year. The red line represents the percent of voters who identified with the Republican party for each given year. After creating this graph, it is clear that there is no direct correlation between political polarization and the number of successful implicitly political films released per year. However, when comparing the year to the percentage of successful implicitly political films, a pattern begins to emerge. Figure 2 isolates the black line from Figure 1, showing only the relationship between the year and the percentage of successful implicitly political films.

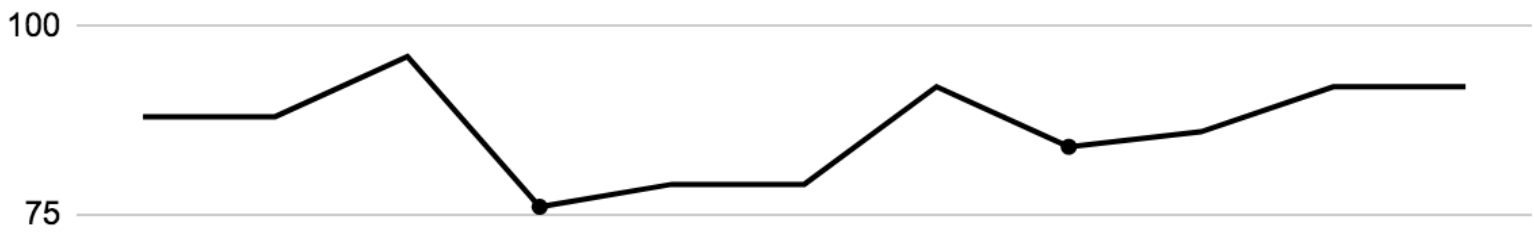

50

25

\begin{tabular}{lllllllllll}
\hline 2009 & 2010 & 2011 & 2012 & 2013 & 2014 & 2015 & 2016 & 2017 & 2018 & 2019
\end{tabular}

Figure 2. Percentage of Implicitly Political Films Per Year

One pattern that this graph shows is seen through Obama's presidency. To elucidate, in Obama's first year of his first term (2009), eighty eight percent of the fifty highest grossing films were implicit. The next year, 2010, this percentage was the same. Then in 2011, the year before the election year, there was a spike in the percent of the successful implicitly political movies, reaching a high of ninety six percent. Then during Obama's fourth year of his first term, 2012, the percent of successful implicitly political films dropped to just seventy six percent. This pattern then began again, with seventy nine percent of the top fifty grossing films of 2013 and 2014 being implicitly political. Then there was a second spike in 2015, Obama's third year of his second term, correlating with the spike in Obama's third year of his first term, that lent ninety two percent of the highest grossing films to be implicitly political. Then once again in 2016 there was a drop in the percent of successful implicitly political films, showing only eighty four percent of the top grossing films were implicitly political. Then in 2017, the percentage went back up, yielding eighty six percent implicitly political films.

However, this pattern begins to change, during the second year of the Trump presidency. Unlike the percentage of successful implicitly political films released during the Obama presidency, the percentage of successful implicitly political films released during Trump's second year does not match that of the first. While the four years during both of Obama's terms followed the same percentage pattern of implicitly political movies (First two years the same, spike during the third year and then drop during the fourth/ election year), Trump's second year breaks this pattern, 
as the percentage of implicitly political films is not equivalent to that from the year before. However, the pattern appears to resume with a one-year delay as the percentages of year two and year three are equivalent.

\section{Discussion}

\section{Correlation Results}

The results shown in the correlational half of this study show no indication that implicitly political films and political polarization are connected. However, this study uncovered a correlation between the year of the presidency and the number of successful implicitly political films. This is seen through the Obama administration as the first and second year of his first term produced the same amount of implicitly political films. Then there was a spike in implicitly political films in his third year and a drop the next year. His second term also followed this same pattern. However, during the Trump administration, the pattern seemed to reappear with a one-year delay, with year two and three matching in percentage rather than year one and year two.

One explanation for the pattern seen through the Obama administration can be rooted to the filmmakers. As filmmakers look to influence their audiences, the year before the election year they may make more implicitly political movies, looking to see the opinions that emerge during the year. This could also mean that filmmakers are weighing out their options for what movies they can make in the next year as to not upset the most popular voters and subsequently lose revenue for their films. However, during election year, filmmakers throw caution to the wind, creating more explicitly political films to get their views across more directly. Rather than implying something, filmmakers want to directly come out and say their opinions as there is limited time for debate in voters' minds when it comes to which political stances they will support in the election.

As for the one-year displacement seen during the Trump administration, this could be attributed to the polarizing nature of Mr. Trump. As Trump is a president that holds more extreme views and takes more extreme actions, filmmakers may have seen it as necessary to continue to make more explicitly political films the year after his election to express their viewpoints of his appointment. Likewise, filmmakers are notoriously liberal and thus the Trump administration must have caused a disruption in the community, therefore interfering with the previous pattern.

However, because of lack of resources and data, there was no way of truly knowing the reasons behind filmmakers' decisions to make the types of movies that they did. Therefore, the implications of this research should be viewed as only speculation rather than theory. In future studies, interviewing top filmmakers could help to understand the perspective of the creators of this pattern and if they were aware of this phenomenon at all.

Table 1. Democratic Survey Responses

\begin{tabular}{|l|c|c|c|c|c|}
\hline & \multicolumn{5}{|c|}{ Number of Responses } \\
\hline Democratic Participant Number & 1 & 2 & 3 & 4 & 5 \\
\hline I am a Republican. & 0 & 0 & 0 & 0 & 0 \\
\hline I am a Democrat. & 5 & 5 & 5 & 5 & 5 \\
\hline $\begin{array}{l}\text { My political views are shaped by the movies that I } \\
\text { watched growing up. }\end{array}$ & 0 & 2 & 3 & 1 & 2 \\
\hline $\begin{array}{l}\text { I disagree with the political views present in the } \\
\text { movies that I watched growing up. }\end{array}$ & 3 & 1 & 2 & 3 & 2 \\
\hline
\end{tabular}


(Table 1 Continued)

\begin{tabular}{|l|c|c|c|c|c|}
\hline Movies play an important role in my life. & 0 & 3 & 4 & 5 & 3 \\
\hline Movies have shaped who I am today. & 0 & 1 & 4 & 3 & 3 \\
\hline Movies influence me. & 0 & 2 & 4 & 5 & 3 \\
\hline
\end{tabular}

When analyzing these survey results, it is evident that there is little to no connection between the five selected Democratic survey participants and their answers. The only two statements that appear to have similar answers are: My political views are shaped by the movies that I watched growing up and I disagree with the political views present in the movies that I watched growing up, with all participant responses coming in on the lower end of the 1-5 spectrum, ranging from 0-3. This means that the Democratic participants overall did not feel that the movies they watched growing up had an immense impact on them growing up, however, the participants did not disagree with the views that were presented in these movies. This could indicate that the Democratic participants did not feel particularly impacted by the movies that they watched growing up because they did not disagree with the viewpoints presented in these movies and therefore were not forced to challenge their beliefs or think about the media that they were experiencing as young children.

Table 2. Republican Survey Responses

\begin{tabular}{|c|c|c|c|c|c|}
\hline \multirow[b]{2}{*}{$\begin{array}{l}\text { Republican Participant } \\
\text { Number }\end{array}$} & \multicolumn{5}{|c|}{ Number of Responses } \\
\hline & 1 & 2 & 3 & 4 & 5 \\
\hline I am a Republican. & 4 & 4 & 4 & 5 & 4 \\
\hline I am a Democrat. & 0 & 1 & 1 & 1 & 1 \\
\hline $\begin{array}{l}\text { My political views are } \\
\text { shaped by the movies } \\
\text { that I watched growing } \\
\text { up. }\end{array}$ & 0 & 0 & 0 & 0 & 1 \\
\hline $\begin{array}{l}\text { I disagree with the po- } \\
\text { litical views present in } \\
\text { the movies that I } \\
\text { watched growing up. }\end{array}$ & 2 & 5 & 0 & 4 & 4 \\
\hline $\begin{array}{l}\text { Movies play an im- } \\
\text { portant role in my life. }\end{array}$ & 1 & 5 & 4 & 1 & 1 \\
\hline $\begin{array}{l}\text { Movies have shaped } \\
\text { who I am today. }\end{array}$ & 1 & 4 & 4 & 0 & 1 \\
\hline Movies influence me. & 2 & 3 & 4 & 1 & 1 \\
\hline
\end{tabular}


When reviewing the Republican survey results, the same two statements that showed similar responses in the Democratic survey show similar responses among Republican survey participants. To reiterate, these two statements are: "My political views are shaped by the movies that I watched growing up and I disagree with the political views present in the movies that I watched growing up." In regard to the first statement, participants generally disagreed with this statement, as four participants answered zero, or strongly disagree, and the last participant voting one, disagree. These responses indicate that the participants did not feel that the movies that they watched growing up influenced their political beliefs now. This could indicate that their political influences came from other areas of their life or that participants felt so strongly in their beliefs that they could not be swayed by the movies that surrounded their childhood.

In regards to the statement, I disagree with the political views present in the movies that I watched growing $u p$, the majority of participants agreed with this statement, with three participants answering a four or five. This could indicate that rather than developing their views in accordance with the films that they watched growing up, Republican participants maintained their views despite the films that they watched growing up. Also, since they disagree with the views present in the movies of their childhood, it can be speculated that these Republican participants did not feel a general connection to the content of the movies that they watched as children, explaining why they feel that these movies did not impact their current political beliefs. To elucidate, Republican participants disagree with the political views present in the movies that they watched growing up, so when watching movies, they became more numb to the content of the movies as they tried to tune out the views that they disagreed with in order to hold firm in their opinions. This can also be seen when looking at Republican responses to the statement Movies influence me. All but one participant answered between 1-3, showing that Republican participants do not feel that movies greatly impact them. This means that although they disagree with the movies that they watched growing up, they do not feel that movies influence them and therefore do not feel that the movies that they watched growing influence their current political behavior. However, this part of the study faces a limitation, as the two other participants answered on the lower end of the spectrum, with one participant answering two and the other answering zero. This disparity could stem from the types of films that the individuals watched in their childhood or perhaps their political indecision as children. Another reason for these outliers could be that as children the participants did not feel that the views in the films were drastic enough to influence their political decision making.

\section{Democratic and Republican Survey Comparison}

In both surveys, participants felt that their political views were not strongly impacted by the movies that they watched growing up. However, when rating whether or not they disagree with the political views present in the movies that they watched growing up, the Democratic and Republican participants answered on opposite ends of the spectrum. Democratic participants did not strongly disagree with the movies that they watched growing up, while the majority of the Republican participants did disagree with the movies that they watched growing up. This means that Democratic participants do not feel their political views were shaped by the movies that they watched growing up and they also do not disagree with the movies that they watched growing up. As for Republican participants, they disagreed with the political views present in the movies that they watched growing up, but they still felt that those movies did not impact their current political views. Republican participants also stated that they did not feel that movies influence them. This explains why even though they strongly disagree with the movies that they watched growing up, Republican participants do not feel that the movies impact their political decision making. This lack of impact could also be because the film industry is seen as a primarily liberal industry.

The similar responses to the first prompt suggest that implicitly political children's movies are more tailored towards Democratic children, meaning that when watching films, Democratic children do not challenge their beliefs or engage in political thinking, while Republican children do not feel that movies influence them, showing that neither party allows movies to impact their political decision making. Therefore, the survey shows that there is no connection 
between implicitly political films and political polarization, as neither party feels that movies greatly impact their political viewpoints, regardless of whether or not they disagree with the views present in the movies that they watch.

\section{Conclusion}

While this study did not fully uncover the relationship between implicitly political films and political polarization, it did unexpectedly reveal the correlation between the year of the presidency and the percentage of successful implicitly political films released per year. This finding is important as it showcases that there is a connection between the presidency and filmmaking. As films have become such a vital part of society and culture, this connection must be evaluated carefully to see how it impacts the minds of unknowing viewers. If this connection is unknowingly impacting viewers, then it is possible to see movies as propaganda. At what point is a line being crossed?

This study also showed that neither Democratic nor Republican adolescents aged 16-18 felt that the movies they watched growing up had a large influence on them. However, Democratic participants generally agreed with the political viewpoints present in the movies that they watched growing up, while Republican children did not. One future study could look to uncover the reason for this difference. Likewise, a future study could uncover if the opinions of these adolescents ring true (movies do not adjust their political behavior), or if these adolescents simply believe that they are not being influenced while their subconscious minds tell a different story. This future study is extremely important as it can help uncover the extent to which media has an influence on young minds. This study could also lead to a debate of ethics surrounding nature vs. nurture. If nurture truly plays as large a role as some believe, then to what extent is it ethical to be shaping the impressionable minds of young people without their knowledge? Is there a way to control this influence? Is our society headed to a place of mind control as seen in George Orwell's 1984? These are all important questions that this study opened the floor to, and the future frontier of research and the world will be greatly influenced by their answers.

A large limitation of this study was time. Because this paper was completed in such a short period, there was not enough time to go back to presidencies before the Obama administration to analyze the patterns presented there. Also, since the study takes place over such a recent time frame, there is no way to analyze the full pattern that will occur during the Trump administration and beyond. Because of this limited time frame this study lacks a fullness that could only be achieved with more time. Hopefully, however, this study comes with inspiration for many more, as the world of film and influence is vastly changing and is infinitely nuanced. With this topic comes endless potential, as we as the human race search to understand why we function the way that we do and how we are all connected.

\section{References}

Barbera, P. (2014). How Social Media Reduces Mass Political Polarization ... Retrieved from http://pablobarbera.com/static/barbera_polarization_APSA.pdf

Bennett, A. (2017, September 29). 'Everybody's happy, everybody's free': Representation and nostalgia in the Woodstock film: Remembering Woodstock: Taylor \& Francis Group. Retrieved fromzhttps://www.taylorfrancis.com/books/e/9781351218665/chapters/10.4324/978135121865-4

Berger, S., Eriksonas, L., \& Mycock, A. (2008, October 15). Narrating the nation: Representations in history, media and the arts. Retrieved from https://pure.hud.ac.uk/en/publications/narrating-the-nation-representations-in-historymedia-and-the-art 
Boxell, L., Gentzkow, M., \& Shapiro, J. M. (2017, October 3). Greater Internet use is not associated with faster growth in political polarization among US demographic groups. Retrieved from https://www.pnas.org/content/114/40/10612

Brody, R. (2013). The Worst Thing about 'Birth of a Nation’ Is How Good It Is. The New Yorker, 1.

Chan, K. (2009). Remade in Hollywood: The global Chinese presence in transnational cinemas (Vol. 1). Hong Kong University Press.

Chinni, D. (2018, March 26) After 20 years, data show dramatic changes in party Alignment. Retrieved from https:/www.nbcnews.com/politics/first-read/after-20-years-data-show-dramatic-changes-Party-alignment-n859821

Cohen, P. (2008, April 23). Animated Bambi Debate Arouses Pastoral Passions. Retrieved from https://www.nytimes.com/2008/04/23/books/23bambi.html

Conover, M. D., Ratkiewicz, J., Francisco, M., Gonçalves, B., Menczer, F., \& Flammini, A. (2011, July). Political polarization on twitter. In Fifth international AAAI conference on weblogs and social media.

Corcoran, P. (2013, August 27). Number of U.S. Movie Screens. Retrieved from https://www.natoonline.org/data/us-movie-screens/.I

Dudkin, I. (2018, November 14). How Technology Changed the Film Industry. Retrieved from https://skywell.software/blog/how-technology-changed-the-film-industry/

Ellsworth, E. (1991). I pledge allegiance: The politics of reading and using educational films. Curriculum Inquiry, 21(1), 41-64. Retrieved from https://www.tandfonline.com/doi/abs/10.1080/03626784.1991.11075351

Englehardt, N. (2017, March 13). Film and Society: How Films Impact Society and Popular Culture. Retrieved from https://platt.edu/blog/film-society-films-impact-society-popular-culture/

Fisher, D. R., Waggle, J., \& Leifeld, P. (2013). Where does political polarization come from? Locating polarization within the US climate change debate. American Behavioral Scientist, 57(1), 70-92.

Gianos, P. L. (1998). Politics and politicians in American film. Greenwood Publishing Group.

Greene, E. (1996). Planet of the Apes as American myth: Race and politics in the films and television series. McFarland.

Levine, L. W. (1985). Hollywood's Washington: Film images of national politics during the Great Depression. Prospects, 10, 169-195.

Lesage, J. (1978). The political aesthetics of the feminist documentary film. Quarterly Review of Film \& Video, $3(4), 507-523$.

Mayer, S. (2015). Political animals: The new feminist cinema. Bloomsbury Publishing. 
Milbrandt, M. K. (2010). Understanding the role of art in social movements and transformation. Journal of Art for Life, $1(1)$.

Neve, B. (2004). Film and politics in America: a social tradition. Routledge.

Orwell, G. (1982). 1984. Mu“nchen: W. Fink.

O'Toole, K., O'TooleKatie, K., \& Durham University. (2019, January 29). The Power of Cinema: 10 Films that Changed the World. Retrieved from https:/www.raindance.org/the-power-of-cinema-10-films-that-changed-theworld/.

Powers, S. P. (2018). Hollywood's America: Social and political themes in motion pictures. Routledge.

Reed, T. V. (2019). The Art of Protest: Culture and Activism from the Civil Rights Movement to the Present. U of Minnesota Press.

Read, T.V. (2005). The Art of Protest: Culture and Activism from the Civil Rights Movement to the Streets of Seattle. Minneapolis: University of Minnesota.

Rose, G. (1994). The cultural politics of place: local representation and oppositional discourse in two films. Transactions of the Institute of British Geographers, 46-60.

The Influence of "The Birth of a Nation". (n.d.). Retrieved from https://www.facinghistory.org/reconstructionera/influence-birth-nation.

Trends in party affiliation among demographic groups. (2018, September 18). Pew Research Center. Retrieved from https:/www.people-press.org/2018/03/20/1-trends-in-party-affiliation-among-demographic-groups/

Watson, A. (2019, October 18). Netflix subscribers count in the U.S.

Watson, A. (2019, February 7). Movie releases in North America from 2000-2018.

What Was the First Movie Ever Made? (2017, November 16). Retrieved from https://headsup.boyslife.org/whatwas-the-first-movie-ever-made/ 